\title{
Construction of Two YAC Contigs in Human Xp11.23-p11.22, One Encompassing the Loci OATL1,GATA,TFE3, and SYP, the Other Linking DXS255 to DXS146
}

\author{
Simon E. Fisher,* Eli Hatchwell,* Aarti Chand,* Nancy Ockenden,* \\ Anthony P. Monaco, $\dagger$ AND IAN W. CRAIG ${ }^{*, 1}$ \\ *Genetics Laboratory, Biochemistry Department, University of Oxford, South Parks Road, Oxford OX1 3QU; and \\ tImperial Cancer Research Fund Laboratories, Institute of M olecular Medicine, John Radcliffe Hospital, \\ Headington, Oxford OX3 9DU, United Kingdom
}

Received March 1, 1995; accepted July 10, 1995

We have constructed two YAC contigs in the $X$ 11.23-p11.22 interval of the human $X$ chromosome, a region that was previously poorly characterized. One contig, of at least $1.4 \mathrm{Mb}$, links the pseudogene OATL1 to the genes GATA1, TFE 3, and SYP and also contains loci implicated in Wiskott-Aldrich syndrome and synovial sarcoma. A second contig, mapping proximal to the first, is estimated to be over $2.1 \mathrm{Mb}$ and links the hypervariable locus DXS255 to DXS146, and also contains a chloride channel gene that is responsible for hereditary nephrolithiasis. We have used plasmid rescue, inverse PCR, and Alu-PCR to generate 20 novel markers from this region, 1 of which is polymorphic, and have positioned these relative to one another on the basis of YAC analysis. The order of previously known markers within our contigs, Xpter-OATL 1GATA - TFE 3 - SYP - DXS255 - DXS146 - Xcen, agrees with genomic pulsed-field maps of the region. In addition, we have constructed a rare-cutter restriction map for a 710-kb region of the DXS255-DXS146 contig and have identified three CpG islands. These contigs and new markers will provide a useful resource for more detailed analysis of Xp11.23-p11.22, a region implicated in several genetic diseases. $\odot 1995$ Academic Press, Inc.

\section{INTRODUCTION}

Genetic studies of the region Xp11.23-p11.22 on the human $X$ chromosome have been greatly aided by the isolation of the marker DXS255, a highly polymorphic locus that maps within Xp11.22 (Fraser et al., 1989). It contains a variable number of tandem repeats (VNTR) motif that is characterized by a 26-bp unit and shows extensive variation of copy number within the population, with a heterozygosity value in excess of $90 \%$ (Fra-

\footnotetext{
${ }^{1}$ To whom correspondence should be addressed. Telephone: 0865 275 327. Fax: 0865275318.
}

ser et al., 1989). It has therefore played an important part in the localization of several disease genes that map to the proximal short arm of the X chromosome, such as the immune deficiency Wiskott-Aldrich syndrome (K wan et al ., 1991) and the eye diseases retinitis pigmentosa 2 (Meitinger et al., 1989), congenital stationary night blindness (Aldred et al., 1992; Musarella et al., 1992), and Aland I sland eye disease (Alitalo et al., 1991).

More recently, linkage has been demonstrated be tween DXS255 and two forms of hereditary nephrolithiasis (kidney stones), known as $\mathrm{X}$-linked recessive nephrolithiasis (XRN) (Scheinman et al., 1993), and Dent's disease (Pook et al., 1993). The latter was found to be associated with a microdeletion involving DXS255 in one pedigree (Pook et al ., 1993). I n addition, independent translocation breakpoints associated with two different types of tissue-specific tumor (synovial sarcoma and renal cell carcinoma) have been mapped to Xp11.23-p11.22 (Sinke et al., 1993).

While the region around DXS255 is thus one of considerable genetic interest, it has not previously been characterized at a physical level. We therefore decided to construct a YAC contig spanning DXS255 to provide a basis for more detailed physical mapping of Xp11.23p11.22 and to aid isolation of disease genes in the region. In doing so, we have made use of additional markers shown to map to the interval including the genes for the synaptic membrane protein synaptophysin (SYP) (Ozcelik et al., 1990), the transcription factor for the enhancer $\mu \mathrm{E} 3$ (TFE3) (Henthorn et al., 1991), and the erythroid-specific transcription factor hGATAl (Caiulo et al., 1991), as well as an ornithine aminotransferase pseudogene (OATL1) (Lafreniere et al., 1991b) and the polymorphic marker DXS146 (Kruse et al., 1986). A combination of linkage analysis and somatic hybrid studies has previously indicated an order of Xpter - OATL 1 - GATA - (TFE3,SYP) - DXS255 - DXS146-Xcen (Cremin et al., 1993; Lafreniere et al., 1991a). We have succeeded in constructing two YAC 
contigs, one spanning DXS255-DXS146 and the other linking the genes GATA, TFE3, and SYP to OATL 1 .

\section{MATERIALS AND METHODS}

Polymerase chain reaction of new STSs. Conditions were as follows for all PCRs; $200 \mu \mathrm{M}$ dNTPs (Amersham); $10 \mathrm{mM}$ Tris- $\mathrm{HCl}$; $50 \mathrm{mM} \mathrm{KCl} ; 1.5 \mathrm{mM} \mathrm{MgCl}$; $1.0 \mu \mathrm{M}$ each primer; Taq polymerase (Boehringer Mannheim). Cycling parameters were $94^{\circ} \mathrm{C}$, 5 min ("hot start"); $94^{\circ} \mathrm{C}, 30 \mathrm{~s} ; \mathrm{T}_{\alpha}, 30 \mathrm{~s} ; 75^{\circ} \mathrm{C}, 30 \mathrm{~s}, 36$ cycles. Details of primer sequences, $\mathrm{T}_{\alpha} \mathrm{S}$, and product sizes are given in Table 2 .

Screening of YAC libraries. Clones were isolated from four YAC libraries. The St. Louis (Brownstein et al., 1989) and ICI (Anand et al., 1990) libraries were available for screening by PCR, while the Nussbaum X-specific library (Lee et al., 1992) could be screened only by hybridization to gridded filters. The ICRF (Larin et al., 1991) library could be screened by either PCR or hybridization. (AII ICRF clones described here were isolated from the $4 \mathrm{X}$ library 900 except for clone B102, which originates from library 905.) Positive clones were confirmed by hybridization of probes to digested YACs. Cultures were grown from several independent colonies of each positive clone and agarose plugs prepared from them using standard methods (Anand et al., 1990). Undigested plugs were run on pulsed-field gels using a "Waltzer" apparatus (Southern et al., 1987), and gels were exposed to UV light for $4 \mathrm{~min}$ prior to blotting. The corresponding filters were hybridized sequentially with human genomic DNA and the (relevant) probe. This allowed determination of YAC sizes and detected any size variation between colony-pure preps of the same YAC due to rearrangement.

Plasmid left end rescue of YACs. DNA from YAC plugs that had been digested to completion with $\mathrm{N}$ del was purified by the GeneClean procedure and ligated under conditions that favor circularization of fragments. Escherichia coli "Top 10" cells (Invitrogen) were transformed by electroporation with the circularized DNA, and ampicillinresistant transformants selected. Clones were sequenced by the dideoxy method (Sanger et al., 1977) with Sequenase version 2.0 (USB), using a primer, 5' AAGTACTCTCGGTAGCCAAG 3', designed from the left YAC arm.

Right end cloning of YACs by inverse PCR (Ochman et al., 1988). DNA from YAC plugs that had been digested to completion with $\mathrm{Hael}$ II was purified by the GeneClean procedure and ligated under conditions that favor circularization. The ligated mix was used as a template for inverse PCR using primers specific for the right arm of pYAC4. Primer sequences were 5' AGTCGAACGCCCGATCTCAA 3' and $5^{\prime}$ TTCAAGCTCTACGCCGGA 3'. Cycling parameters were $94^{\circ} \mathrm{C}, 5 \mathrm{~min} ; 94^{\circ} \mathrm{C}, 1 \mathrm{~min} ; 55^{\circ} \mathrm{C}, 1 \mathrm{~min} ; 75^{\circ} \mathrm{C}, 2 \mathrm{~min}, 35$ cycles. The product was digested with $\mathrm{ECORI}$ and $\mathrm{HadII}$ and cloned into pUC9 using standard techniques. One left end described here, L(F081), was isolated by inverse PCR; the protocol was identical to that for right ends, but primer sequences were different: 5' AAGTACTCTCGGTAGCCAAG 3' and 5' TCAGAGTGAAATTTATACTAA 3'.

Alu-PCR of YACs (Nelson et al., 1989). DNA from melted YAC plugs was used as a template for PCR using the following primers: 5' TCATGGATCCGCGAGACTCCATCTCAAA 3' and 5' TCATGTCGACGCGAGACTCCATCTCAAA $3^{\prime}$. Cycling parameters were $94^{\circ} \mathrm{C}, 5 \mathrm{~min} ; 94^{\circ} \mathrm{C}, 1 \mathrm{~min} ; 55^{\circ} \mathrm{C}, 1 \mathrm{~min} ; 75^{\circ} \mathrm{C}, 2 \mathrm{~min}, 35 \mathrm{cycles}$. The product was digested with $\mathrm{BamHI}$ and Sall and cloned into pUC9 using standard techniques.

Rarecutter restriction mapping of YACs. YAC DNA (in plugs) was digested with a range of amounts of restriction enzyme $(0.1,0.3$, 1,5 , and 15 units) for $1 \mathrm{~h}$ in the appropriate buffer. Digests were separated by PFGE, and gels were exposed to UV light for $4 \mathrm{~min}$ prior to blotting. Blots were probed sequentially with left and right YAC vector arm and then with any internal markers that needed to be localized.

\section{RESULTS}

Previously characterized probes were used to isolate positive clones from YAC libraries by hybridization and/or PCR. Pulsed-field gel electrophoresis was used to size YACs and was also instrumental in detecting those clones that were susceptible to rearrangement as described under Materials and Methods. YAC details are given in Table 1.

Terminal sequences of YAC inserts were isolated using plasmid rescue for the left end and inverse PCR (Ochman et al., 1988) for the right end. These clones are referred to as $L(Y A C I D)$ and $R(Y A C I D)$, respectively. Alu-PCR of YAC DNA (Nelson et al., 1989) was also used to generate internal markers (referred to as $A(Y A C$ ID)). The sequence data obtained from the majority of these novel probes were used to select primers for use as sequence-tagged sites (STSs), which are listed in Table 2. The approximate location of new markers was established by analysis of somatic cell hybrids and monochromosomal hybrid cell lines to screen out those that did not originate from Xp11.2. Overlap between YAC clones was detected by the presence of a common marker. Those novel Xp11.2 specific probes that were found to be absent from overlapping YACs represented the most distal or proximal markers of their respective contigs and were therefore used to rescreen YAC libraries for new clones. Contigs were oriented with respect to the centromere/tel omere of the $X$ chromosome on the basis of previously ordered clones and by physical mapping using translocation hybrids.

\section{A YAC Contig Linking OATL 1, GATA, TFE3, and SYP}

YACs were isolated by screening with OATL1, GATA, and TFE 3. The orientation of the OATL 1 clones with respect to the $X$ chromosome was established by mapping novel probes from these YACs against the synovial sarcoma translocation breakpoint. L(F0701) at the distal end of the cluster was also present in ICRFy900C1022, the most proximal YAC in a previously characterized contig around DXS426/TIMP (Coleman et al., 1994). Further analysis with newly generated markers indicated that the OATL 1, GATA, and TFE 3 clones were contiguous (Fig. 1). Three GATA YACs (27GF2, B 102, and 4542) showed a susceptibility to deletion of the region containing the GATA locus, suggesting that there is region-specific instability.

Extensive screening of the ICRF, ICI, St. Louis, and Nussbaum libraries has resulted in the isolation of only one SYP YAC, E021, the left end of which was found to be autosomal. E021 was also shown to contain the TFE 3 locus, suggesting that we have established a complete contig from OATL 1 to SYP. However, it should be noted that mapping of SYP and TFE 3 within a rarecutter restriction map of E021 showed that they both map within $\sim 125 \mathrm{~kb}$ of the right end (data not shown), and this conflicts with pulsed-field genomic data, which indicate a SYP - TFE 3 distance of $\sim 400 \mathrm{~kb}$ (Derry et al., 1994). It therefore seems likely that E021 has undergone a deletion of material between the two markers. 
TABLE 1

Details of YACs from Xp11.23-p11.22

\begin{tabular}{|c|c|c|c|c|c|c|c|}
\hline $\begin{array}{l}\text { YAC } \\
\text { ID }\end{array}$ & $\begin{array}{l}\text { Alternative } \\
\text { name }\end{array}$ & Library & I solated with & Size $(k b)$ & $\begin{array}{l}\text { Left } \\
\text { end }\end{array}$ & $\begin{array}{l}\text { Right } \\
\text { end }\end{array}$ & Other markers present \\
\hline \multirow[t]{3}{*}{ F0701 } & OATL $1 / 6$ & ICRF & OAT CDNA & 600 & $\mathrm{x}$ & $\mathrm{x}$ & L(OATL 1/11) \\
\hline & OATL1/3 & ICRF & OAT CDNA & 2000 & Aut & & L(F 0701), L(OATL 1/11) \\
\hline & OATL1/11 & ICRF & OAT CDNA & 800 & $x$ & & \\
\hline F0501 & OATL1/2 & ICRF & OAT CDNA & 550 & $\mathrm{x}$ & & L(OATL $1 / 11), A(F 0501), R(3578)$, WASP \\
\hline $27 G F 2$ & PTO & $\mathrm{ICl}$ & $A(F 0501)$ & $780 / 750^{\mathrm{b}}$ & & & R(3578), WASP, GATA \\
\hline $\mathrm{C} 01160$ & GATA/1 & ICRF & GATA CDNA & 120 & & & \\
\hline B102 & GATA $/ 2$ & ICRF $^{\mathrm{a}}$ & GATA CDNA & $300 / 200^{b}$ & $\mathrm{x}$ & $\mathrm{x}$ & \\
\hline 3578 & GATA $/ 3$ & St. Louis & GATA CDNA & 125 & & $x$ & WASP \\
\hline 4542 & GATA/4 & St. Louis & GATA CDNA & $300+160^{c}$ & & & \\
\hline E021 & TFE 3-SYP/1 & ICRF & SYP PCR assay & 375 & Aut & $\mathrm{x}$ & TFE3 \\
\hline $5 \mathrm{H} 12$ & TFE $3 / 2$ & Nussbaum & TFE 3 CDNA & 120 & & & \\
\hline $12 \mathrm{E} 11$ & TFE $3 / 3$ & Nussbaum & TFE 3 CDNA & 230 & & & $L(B 102)$ \\
\hline E0250 & FDTM $/ 1$ & ICRF & L(B0617) & $700 / 680 / 660^{\mathrm{b}}$ & $x$ & & $A(E 0250), R(27 C B 12)$ \\
\hline $16 C D 8$ & FDTM $/ 2$ & $\mathrm{ICl}$ & L(B0617) & $400+290^{c}$ & & & $R(27 C B 12), L(E 0250)$ \\
\hline 27CB12 & FDTM $/ 3$ & $\mathrm{ICl}$ & L(B0617) & $270 / 250^{\mathrm{b}}$ & & $\mathrm{x}$ & $L(E 0250)$ \\
\hline 36HB8 & FDTM/4 & $\mathrm{ICl}$ & L(B0617) & 345 & & $\mathrm{x}$ & R(27CB12), L(E0250) \\
\hline B0617 & DTM/1 & ICRF & $L(F 1001)$ & 380 & $x$ & $\mathrm{x}$ & $L(E 0250), R(36 H B 8)$ \\
\hline $22 A B 3$ & $\mathrm{DTM} / 2$ & $\mathrm{ICl}$ & L(F1001) & 280 & & & L(E 0250), R(36HB8) \\
\hline F1001 & DXS255/1 & ICRF & M27beta & 1135 & $\mathrm{x}$ & Aut & R(B0617), CIC-5, L(6129) \\
\hline 6129 & DXS255/2 & St. Louis & DXS255 & 185 & $\mathrm{x}$ & & L(F 1001), R(B0617), ClC-5 \\
\hline C0191 & PTM/1 & ICRF & $L(6129)$ & 365 & & & CiC-5, L(G0201) \\
\hline F 1101 & pTAK $/ 1$ & ICRF & PTAK8 & 580 & $\mathrm{x}$ & $\mathrm{x}$ & $L(F 081)$ \\
\hline F1201 & PTAK $/ 2$ & ICRF & pTAK 8 & 1000 & Aut & & $R(F 1101), L(F 081)$ \\
\hline G0101 & PTAK $/ 3$ & ICRF & PTAK 8 & 300 & & & $R(F 1101)$ \\
\hline G0201 & PTAK $/ 4$ & ICRF & pTAK 8 & 900 & $x$ & & $R(F 1101), L(F 081)$ \\
\hline B0115 & & ICRF & $L(F 1101)$ & 520 & $\mathrm{x}$ & & $L(F 081)$ \\
\hline F 081 & & ICRF & L(F1101) & 550 & $\mathrm{x}$ & $\mathrm{x}$ & L(B0115) \\
\hline A0926 & & ICRF & $L(F 1101)$ & 380 & $\mathrm{x}$ & & L(F081), L(B0115), R(F081) \\
\hline
\end{tabular}

Note YACs are listed in the order Xpter-cen. A space separates the OATL1-GATA-TFE3-SYP clones from those of the DXS255DXS146 cluster. Details of YAC libraries are given under Materials and Methods. L(YAC ID), left end of YAC; R(YAC ID), right end of YAC; $A(Y A C I D)$, Alu-PCR probe for YAC; $X$, end clone $X$-specific; Aut, end clone autosomal, indicating chimeric $Y A C$.

${ }^{a}$ YAC isolated from ICRF library 905.

b YAC rearranging.

c Two forms of the same YAC present in all colony-pure preps.

The gene responsible for Wiskott-Aldrich syndrome (termed WASP) has recently been identified (Derry et al., 1994). We used a probe prepared from the first two exons of this gene to localize it within our YAC contig (Fig. 1). Rare-cutter restriction mapping of YACS (Chand et al., submitted) indicates that the OATL1GATA-TFE3-SYP cluster is a minimum of $\sim 1.4$ $\mathrm{Mb}$ in size. The order of markers in this contig was found to be Xpter - L(F 0701)-L(OATL 1/11)- OATL 1$A(F 0501)$ - R(3578) - WASP - GATA - L(B102) - TFE3 SYP - Xcen.

\section{A YAC Contig Spanning DXS255 and DXS146}

Initially YACs were isolated using M27beta (which recognizes the DXS255 locus) and PTAK 8 (which recognizes the DXS146 locus). Analysis using novel markers generated from these YACs showed that the DXS255 clones did not overlap with the DXS146 clones. However, the gap between the two clusters was bridged by the identification of a new clone (C0191), which was found to contain terminal markers from both clusters (Fig. 2). In addition, this result enabled the orientation of the contig relative to the $X$ chromosome to be determined, since linkage analysis and physical mapping have established that DXS146 lies centromeric to DXS255 (Cremin et al., 1993; Willard et al., 1994).

The DXS255-DXS146 contig was extended in the proximal direction by one walking step (using L (F 1101) and in the distal direction with two steps (first with $L(F 1001)$ and then with $L(B 0617)$ ). Three of the YACs isolated with $L$ (B0617) were found to be clonally unstable. F or example, cultures grown from three single colonies of a streak of E 0250 yielded clones of 700, 680, or $660 \mathrm{~kb}$, all containing the L(B0617) marker. Mapping of $L(E 0250)$ indicated that E0250 was oriented with its left end toward Xcen. Attempts to isolate R(E 0250) using inverse PCR were unsuccessful, due to a lack of appropriate enzyme sites at the right end of the YAC insert (see Materials and Methods). An alternative $X$ specific marker generated from this YAC, $A(E 0250)$, is therefore the most distal STS in the DXS255-DXS146 cluster, but was found to be absent from the OATL1GATA1-TFE3-SYP contig.

A $710-k b$ region of the contig, centered on the 
TABLE 2

Details of PCR Assays Developed from New Markers in Xp11.23-p11.22 YAC Contigs

\begin{tabular}{|c|c|c|c|c|}
\hline $\begin{array}{l}\text { Marker } \\
\text { name }\end{array}$ & DXS No. & Primer sequences ( $5^{\prime}$ to $\left.3^{\prime}\right)$ & $\begin{array}{c}\mathrm{T}_{\mathrm{a}} \\
\left({ }^{\circ} \mathrm{C}\right)\end{array}$ & $\begin{array}{l}\text { Product } \\
\text { size (bp) }\end{array}$ \\
\hline L(F0701) & & $\begin{array}{l}\text { CAGCCACCAGTAGCAGTAGGG } \\
\text { GAGCAGCTGTACTGTTCTGGG }\end{array}$ & 63 & 149 \\
\hline L(OATL1/11) & & $\begin{array}{l}\text { AAGGGAGAGGGAATGAAA } \\
\text { CACATCCGAATACAACAAGA }\end{array}$ & 56 & 150 \\
\hline$A(F 0501)$ & 6664 & $\begin{array}{l}\text { TAAGGCAGATACAGTCTC } \\
\text { GGGCTGGAAGAATGGTGT }\end{array}$ & 59 & 359 \\
\hline L(B102) & 6665 & $\begin{array}{l}\text { TACAGGCATCCACCACCC } \\
\text { AGGCAGGAAAAGCATCTAAGC }\end{array}$ & 55 & 225 \\
\hline$A(E 0250)$ & & $\begin{array}{l}\text { GCAGACTCAAAAGGCCACAT } \\
\text { TGCATTCACAAAGTTGTGCA }\end{array}$ & 55 & 215 \\
\hline$L(B 0617)^{a}$ & 6666 & $\begin{array}{l}\text { СTTCTGGACCTGCAAAGAGG } \\
\text { CCCTGAGCAATAGAAGTTAAACC }\end{array}$ & 55 & $170-200$ \\
\hline L(F 1001) & 6850 & $\begin{array}{l}\text { TTGTCTCTCTTCACCTTTTGC } \\
\text { GGTTGTTTTCGTTTACCCTC }\end{array}$ & 52 & 106 \\
\hline L(6129) & 6851 & $\begin{array}{l}\text { GACTCTTGAGGGAGTCACAG } \\
\text { ACTCATTGTACCTCCCAGC }\end{array}$ & 50 & 139 \\
\hline L(G0201) & 6852 & $\begin{array}{l}\text { GTTAAGCATACCAACAAAAGTGGCG } \\
\text { GAAAGCTCCTCCTTCAGAGCCAATA }\end{array}$ & 60 & 169 \\
\hline L(F 1101) & & $\begin{array}{l}\text { TCTTCAAAATCCCTGGCTTCTTTTC } \\
\text { TTCCACTCACTTTCAATCTCATATTTC }\end{array}$ & 60 & 129 \\
\hline L(A0926) & 6667 & $\begin{array}{l}\text { CCACACAGAGAATGATTTCAGA } \\
\text { TCAGTTGAATTTTTCAGCTCTG }\end{array}$ & 52 & 104 \\
\hline
\end{tabular}

Note. Markers are listed in Xpter - cen order, as deduced from YAC analysis; $L(Y A C I D)$, left end clone of $Y A C$; R(YAC ID), right end clone of YAC; $A\left(Y A C\right.$ ID), Alu-PCR product from YAC; $T_{a}$, annealing temperature. Additional details of PCR amplification conditions are given under Materials and Methods. Although the marker R(F1101) has been assigned a DXS number (DXS6853), it has not been converted into an STS and is therefore not listed.

${ }^{a}$ PCR assay from L(B0617) spans a polymorphic CA repeat and therefore gives products of varying size.

DXS255 YACs, was restriction mapped with six rare cutters (Fig. 2, Top). Seven of the novel markers generated from this contig, as well as DXS255, were positioned within this map. We have also localized CIC-5, a gene implicated in Dent's disease, which we recently isolated using the 6129 Y AC (Fisher et al., 1994). Three putative CpG islands were identified within this 710kb region (Fig. 2, Top).

On the basis of the above restriction map we were able to deduce that the entire E0250-B0617-6129-
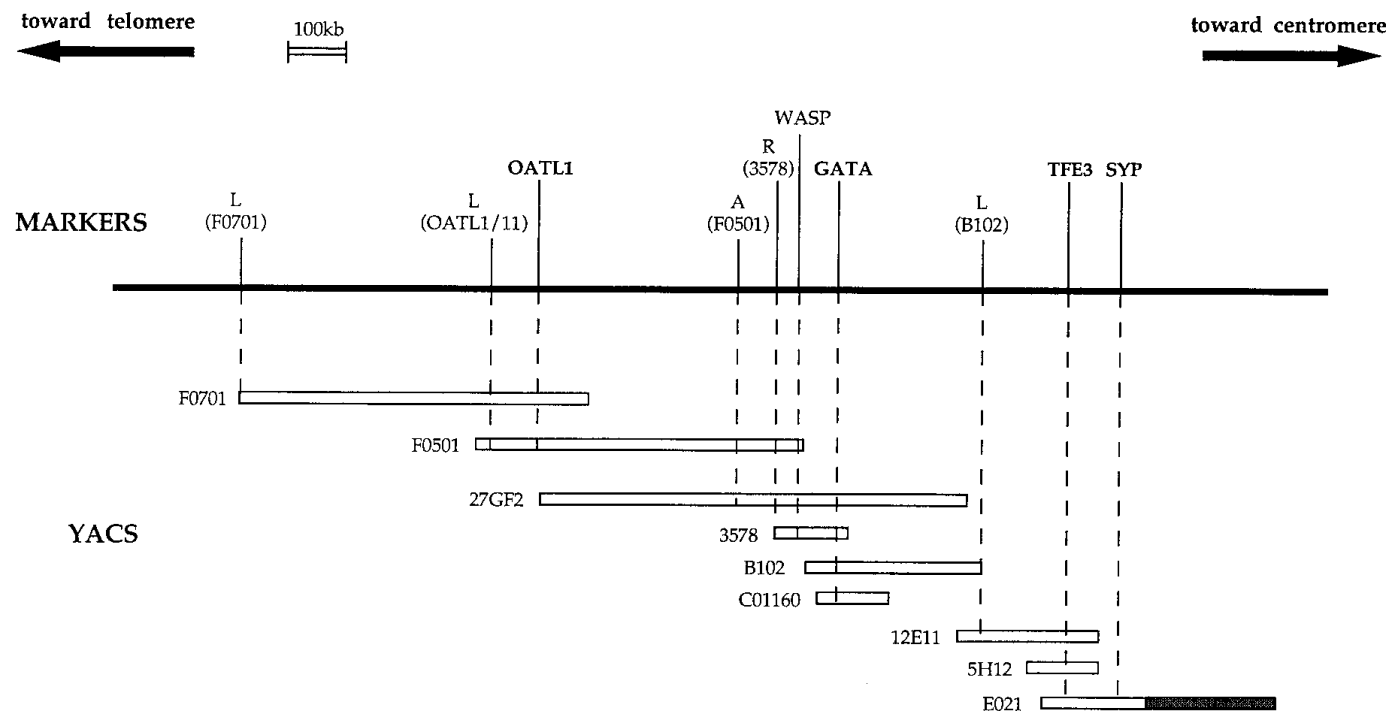

FIG. 1. YACs and markers in the OATL1-GATA-TFE3-SYP cluster. L(YAC ID), left end clone of YAC; R(YAC ID), right end clone of YAC; A(YAC ID), Alu-PCR product isolated from YAC. Autosomal regions of chimeric YACs are indicated by shading. Clones are drawn to scale, but the extent of YAC overlap has not been established for all clones in the contig; hence, physical distances between markers are not al ways accurately represented. L(F 0701) links up with a previously published YAC contig around DXS426/TIMP (Coleman et al., 1994). Further details of YACs and markers are given in Tables 1 and 2. 


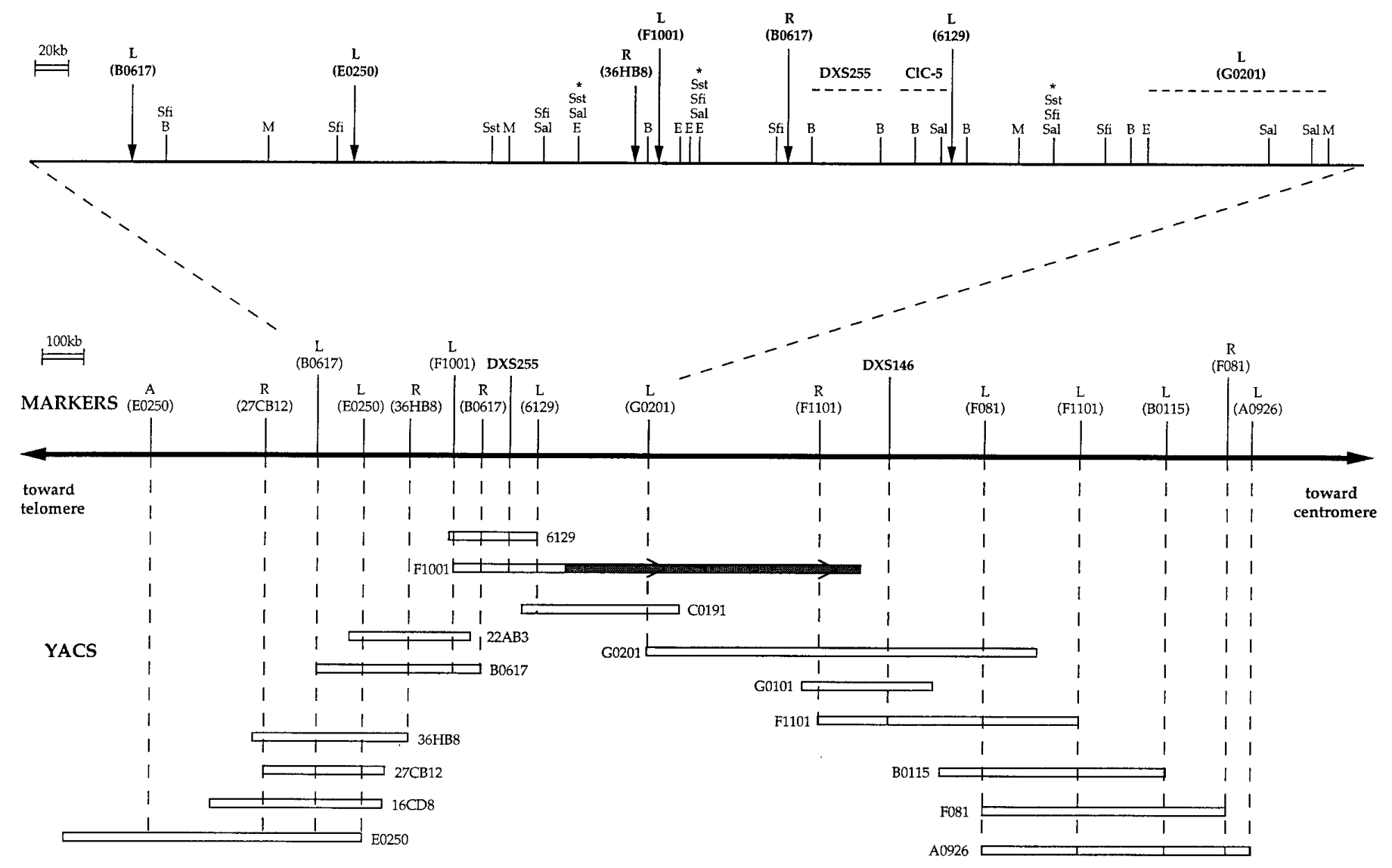

FIG. 2. (Bottom) YACs and markers in the DXS255-DXS146 cluster. L(YAC ID), left end clone of YAC; R(YAC ID), right end clone of YAC; $A(Y A C$ ID), Alu-PCR product isolated from YAC. Autosomal regions of chimeric YACs are indicated by shading. Clones are drawn to scale, but the extent of YAC overlap has not been established for all clones in the contig; hence, physical distances between markers are not always accurately represented. Further details of YACs and markers are given in Tables 1 and 2. Note that while marker analysis indicates that F081 should be smaller than A0926, YAC sizing on a pulsed-field gel has established that it is in fact larger, suggesting that one of these clones has undergone a rearrangement. (Top) Rare-cutter restriction map for a 710-kb region of the contig. B, BssHII; E, Eagl ; M, Mlul; Sal, Sal I; Sfi, Sfil; Sst, SstII. Scale is given. Arrows indicate positions of novel markers. DXS255, CIC-5, and L (G0201) localization is imprecise; therefore, their positions are denoted by dotted lines. The three rare-cutter islands are marked with asterisks. The map was assembled from partial digests of E 0250, 36HB8, B0617, 6129, F 1001, and C0191 after discounting chimeric regions.

C0191 region of the contig spans $\sim 1.3 \mathrm{Mb}$ of genomic DNA. Combined with data from the sizing of nonchimeric, nonoverlapping YACs in the more proximal part of the cluster, this suggests a minimum size of $\sim 2.1 \mathrm{Mb}$ for the DXS255-DXS146 contig. The overall order of new markers on the basis of YAC analysis is Xpter - A (E 0250)-R (27CB12)-L (B0617)-L (E0250)$R(36 H B 8)-L(F 1001)-R(B 0617)-D X S 255-C I C-5-$ $L(6129)-L(G 0201)-R(F 1101)-D X S 146-L$ (F081)$L(F 1101)-L(B 0115)-R(F 081)-L(A 0926)-X c e n$.

\section{DISCUSSION}

We have constructed a $>2.1-\mathrm{Mb}$ YAC contig spanning the loci DXS255 and DXS146 and a >1.4-Mb YAC contig linking the markers OATL 1, GATA, TFE 3, and SYP to aid further analysis of Xp11.23-p11.22, a region that was previously only poorly characterized. These contigs include 28 YACs and 20 novel Xp11.23p11.22-specific physical markers, which wehavegener- ated using plasmid rescue, inverse PCR, and Alu-PCR and ordered on the basis of YAC analysis. STSs have been developed for 11 of these new markers, and one contains a polymorphic CA repeat. The order of previously cloned markers used to construct the contigs was found to be Xpter-OATL1-GATA-TFE3-SYPDXS255-DXS146-Xcen, which agrees with genomic pulsed-field data for the region (Willard et al., 1994). We are currently screening YAC libraries with $A(E 0250)$, the most distal marker that we have isolated from the DXS255-DXS146 Y AC cluster, to bridge the gap between this and the OATL1-GATA - TFE 3-SYP contig. The genomic distance between SYP and DXS255 has not yet been established and may range from 1.2 to $2.2 \mathrm{Mb}$ (Willard et al., 1994).

Several difficulties may be encountered when attempting to construct a series of overlapping YAC clones that accurately represent a chromosomal region. Chimeric YACs constitute a significant proportion of clones within currently available libraries; estimates of chimerism range from $\sim 11 \%$ of clones in the Nuss- 
baum X-specific library (Lee et al., 1992) to 40-50\% in the CEPH mega-YAC library (Cohen et al., 1993). This can present problems for the strategy of chromosome walking adopted here, which relies on the isolation of new markers from the left and/or right ends of each YAC, and it was therefore essential to determine the $X$-specificity of each probe generated. In addition, some regions of the genome are inherently unstable when cloned into YACS; inserts may rearrange, resulting in the isolation of size variants from a single YAC clone, and this was found for several clones described here. In certain cases YACs may even del ete the region containing the marker used to select the clone, initially, as observed with the GATA YACs.

We have overcome problems of chimerism and rearrangement by isolating several different overlapping clones for all regions of our contigs. However, it is apparent that the region around the SYP gene is particularly unstable in YACs. After screening of four independent libraries with this probe, only one positive clone was isolated (E021), a 375-kb YAC, which was also found to contain the TFE 3 locus. Further analysis of the clone indicated that it was chimeric, and comparison between therare-cutter restriction map of this YAC and genomic pulsed-field maps around SYP and TFE 3 suggested that it had rearranged to delete several hundred kilobases of DNA between the loci. A second isolate of E 021 was found to contain only the TFE 3 locus, even though it was larger than the first (390 kb), and another group has reported that E021 is positive only for the SYP locus (Willard et al., 1994). These observations suggest that the clone may have originated as a larger YAC containing SY P and TFE 3 and then deleted different portions to yield the different isolates. Given the difficulties experienced by us and other groups in isolation of stable, nonchimeric YACs containing SYP, it may be necessary to use some other vector, such as the $\mathrm{P} 1$ system (Sternberg, 1990), for further study.

A comprehensive YAC contig of a region provides a good starting point to aid isolation of translocation breakpoints and disease genes. We have already used YACs and markers from one of the contigs presented here to isolate by positional cloning the gene responsible for Dent's disease, a kidney-specific chloride channel, and have shown it to lie between $L(6129)$ and DXS255 (Fisher et al., 1994). Recently, another group has been successful in identifying a gene (termed WASP) from the region around the GATA locus, which is mutated in patients with Wiskott-Aldrich syndrome (Derry et al., 1994). Although they position this new locus between GATA and TFE 3, data from our contig suggest that it maps to the OATL 1-GATA interval. A gene that is disrupted by the synovial sarcoma $\mathrm{X} ; 18$ translocation breakpoint in the OATL 1 cluster has also recently been identified (Clarke et al., 1994).

The YAC contigs that we have produced will provide a useful resource for the identification of new polymorphic markers (such as L(B0617)), which may help to refine the localization of diseases such as retinitis pig- mentosa 2 . The contigs are being mapped with rarecutter restriction enzymes to aid physical mapping of loci and to identify CpG islands that may be associated with the control regions of new genes (Lindsay and Bird, 1987), with the ultimate aim of constructing a complete transcript map of Xp11.23-p11.22.

\section{ACKNO WLEDGMENTS}

We are grateful to S-P. Kwan for ICRFy905B102. We also thank J. Knight, S. Orkin, J. Puck, and V. Ramesh for providing probes used in this study. This work was supported by the Wellcome Foundation (E.H./A.C.) and by an HGMP studentship from the MRC (S.E.F.).

\section{REFERENCES}

Aldred, M. A., Dry, K. L., Sharp, D. M., Van Dorp, D. B., Brown, J ., Hardwick, L. J ., Lester, D. H., Pryde, F. E., Teague, P. W., J ay, M., Bird, A. C., J ay, B., and Wright, A. F. (1992). Linkage analysis in $X$-linked congenital stationary night blindness. Genomics 14: 99- 104.

Alitalo, T., Kruse, T. A., Forsius, H., Erikssson, A. W., and de la Chapelle, A. (1991). Localization of the Aland Island eye disease locus to the pericentromeric region of the $X$ chromosome by linkage analysis. Am. J . Hum. Genet. 48: 31- 38.

Anand, R., Riley, J. H., Butler, R., Smith, J. C., and Markham, A. F. (1990). A 3.5 genome equivalent multi access YAC library: Construction, characterization, screening and storage. Nucleic Acids Res. 18: 1951- 1956.

Brownstein, B. H., Silverman, G. A., Little, R. D., Burke, D. T., Korsmeyer, S. J ., Schlessinger, D., and Olson, M. V. (1989). I solation of single-copy human genes from a library of yeast artificial chromosome clones. Science 244: 1348- 1351.

Caiulo, A., Nicolis, S., Bianchi, P., Zuffardi, O., Bardoni, B., Maraschio, P., Ottolenghi, S., Camerino, G., and Giglioni, B. (1991). Mapping the gene encoding the human erythroid transcription factor NFE 1-GF 1 to Xp11.23. Hum. Genet. 86: 388- 390.

Clarke, J., Rocques, P. J ., Crew, A. J ., Gill, S., Shipley, J ., Chan, A. M. L., Gusterson, B. A., and Cooper, C. S. (1994). Identification of novel genes, SYT and SSX, involved in the $t(X ; 18)(p 11.2 ; q 11.2)$ translocation found in human synovial sarcoma. Nature Genet. 7: 502-508.

Cohen, D., Chumakov, I., and Weissenbach, J . (1993). A first-generation physical map of the human genome. Nature 366: 698-701.

Coleman, M. P., Nemeth, A. H., Campbell, L., Raut, C. P., Weissenbach, J ., and Davies, K. E. (1994). A 1.8-M b YAC contig in Xp11.23: Identification of CpG islands and physical mapping of CA repeats in a region of high gene density. Genomics 21: 337-343.

Cremin, S. M., Greer, W. L., Bodok-Nutzati, R., Schwartz, M., Peacocke, M., and Siminovitch, K. A. (1993). Linkage of WiskottAldrich syndrome with three marker loci, DXS426, SYP and TFE 3, which map to the Xp11.3-p11.22 region. Hum. Genet. 92: 250253.

Derry, J . M. J ., Ochs, H. D., and Francke, U. (1994). I solation of a novel gene mutated in Wiskott-Aldrich syndrome. Cell 78: 635644.

Fisher, S. E., Black, G. C. M., Lloyd, S. E., Hatchwell, E., Wrong, O., Thakker, R. V., and Craig, I. W. (1994). I solation and partial characterization of a chloride channel gene which is expressed in kidney and is a candidate for Dent's disease (an X-linked hereditary nephrolithiasis). Hum. Mol. Genet. 3: 2053- 2059.

Fraser, N. J ., Boyd, Y., and Craig, I. (1989). I solation and characterization of a human variable copy number tandem repeat at Xcenp11.22. Genomics 5: 144-148.

Henthorn, P. S., Stewart, C. C., Kadesch, T., and Puck, J . M. (1991). 
The gene encoding human TFE 3, a transcription factor that binds the immunoglobulin heavy-chain enhancer, maps to Xp11.22. Ge nomics 11: 374-378.

Kruse, T. A., Ahrens, P., Albertsen, H. M., J orgensen, B., and Vestergaard, S. R. (1986). An anonyomous single copy X-chromosome clone, pTAK-8, identifies a frequent RFLP at Xp11-q12. Nucleic Acids Res. 14: 1921.

Kwan, S.-P., Lehner, T., Hagemann, T., Lu, B., Blaese, M., Ochs, H., Wedgewood, R., Ott, J ., Craig, I. W., and Rosen, F. S. (1991). Localization of the gene for Wiskott-Aldrich syndrome between two flanking markers, TIMP and DXS255, on Xp11.22-Xp11.3. Genomics 10: 29- 33.

Lafreniere, R. G., Brown, C. J ., Powers, V. E., Carrel, L., Davies, K. E., Barker, D. F., and Willard, H. F. (1991a). Physical mapping of 60 DNA markers in the p21.1-q21.3 region of the human $X$ chromosome. Genomics 11: 352-363.

Lafreniere, R. G., Geraghty, M. T., Valle, D., Shows, T. B., and Willard, H. F. (1991b). Ornithine aminotransferase-related se quences map to two nonadjacent intervals on the $\mathrm{X}$ chromosome short arm. Genomics 10: 276- 279.

Larin, Z., Monaco, A. P., and Lehrach, H. (1991). YAC libraries containing large inserts from mouse and human DNA. Proc. Natl. Acad. Sci. USA 88: 4123-4127.

Lee, J . T., Murgia, A., Sosnoki, D. M., Olivos, I. M., and Nussbaum, R. L. (1992). Construction and characterization of a yeast artificial chromosomelibrary for Xpter - Xq27.3: A systematic determination of cocloning rate and X-chromosome representation. Genomics 12: $526-533$.

Lindsay, S., and Bird, A. P. (1987). Use of restriction enzymes to detect potential gene sequences in mammalian DNA. Nature 327: 336- 338.

Meitinger, T., Fraser, N. A., Lorenz, B., Zrenner, E., Murken, J ., and Craig, I. W. (1989). Linkage of X-linked retinitis pigmentosa to the hypervariable DNA marker M27beta (DXS255). Hum. Genet. 81: 283- 286.

Musarella, M. A., Kirschgessner, C., Trofatter, J ., Miyake, Y., Mets, M., and De Gennaro, L. (1992). Assignment of the gene for incomplete congenital stationary night blindness (CSNB2) to proximal Xp. Am. J. Hum. Genet. 51: 772.
Nelson, D. L., Ledbetter, S. A., Corbo, L., Victoria, M. F., RamirezSolis, R., Webster, T. D., Ledbetter, D. H., and Caskey, C. T. (1989). Alu polymerase chain reaction: A method for rapid isolation of human-specific sequences from complex DNA sources. Proc. Natl. Acad. Sci. USA 86: 6686-6690.

Ochman, H., Gerber, A. S., and Hartl, D. L. (1988). Genetic applications of an inverse PCR. Genetics 120: 621-623.

Ozcelik, T., Lafreniere, R. G., Archer, B. T., J ohnston, P. A., Willard, H. F., Francke, U., and Sudhof, T. C. (1990). Synaptophysin: Structure of the human gene and assignment to the $X$ chromosome in man and mouse. Am. J. Hum. Genet. 47: 551-561.

Pook, M. A., Wrong, O., Wooding, C., Norden, A. G. W., Feest, T. G., and Thakker, R. V. (1993). Dent's disease, a renal Fanconi syndrome with nephrocalcinosis and kidney stones, is associated with a microdeletion involving DXS255 and maps to Xp11.22. Hum. Mol. Genet. 2: 2129-2134.

Sanger, F., Nicklen, S., and Coulsen, A. R. (1977). DNA sequencing with chain-terminating inhibitors. Proc. Natl. Acad. Sci. USA 74: 5463-5467.

Scheinman, S. J ., Pook, M. A., Wooding, C., Pang, J . T., Fryomyer, P. A., and Thakker, R. V. (1993). Mapping the gene causing $X$-linked recessive nephrolithiasis to Xp11.22 by linkage analysis. J . Clin. Invest. 91: 2351-2357.

Sinke, R. J ., De Leeuw, B., J anssen, H. A. P., Weghuis, D. O., Suijkerbuijk, R. F., Meloni, A. M., Gilgenkrantz, S., Berger, W., Ropers, H. H., Sandberg, A. A., and Geurts van Kessel, A. (1993). Localization of $X$ chromosome short arm markers relative to synovial sarcoma and renal adenocarcinoma-associated translocation breakpoints. Hum. Genet. 92: 305-308.

Southern, E. M., Anand, R., Brown, W. R. A., and Fletcher, D. S. (1987). A model for the separation of large DNA molecules by crossed field gel electrophoresis. Nucleic Acids Res. 15: 5925- 5943.

Sternberg, N. (1990). A bacteriophage P1 cloning system for the isolation, amplification, and recovery of DNA fragments as large as 100kbp. Proc. Natl. Acad. Sci. USA 87: 103- 107.

Willard, H. F., Cremers, F., Mandel, J . L., Monaco, A. P., Nelson, D. L., and Schlessinger, D. (1994). Report of the fifth international workshop on human $X$ chromosome mapping. Cytogenet. Cell Genet. 67: 295- 358. 